\title{
Working with Homeless Women and Children: Opportunities for Training
}

Lance D. Clawson, M.D.

121st Army Evacuation Hospital, Seoul Korea

Ronald J. Koshes, M.D.

F. Edward Herbert School of Medicine, Fort Lee, Virginia

Follow this and additional works at: https://jdc.jefferson.edu/jeffjpsychiatry

Part of the Psychiatry Commons

Let us know how access to this document benefits you

\section{Recommended Citation}

Clawson, M.D., Lance D. and Koshes, M.D., Ronald J. (1990) "Working with Homeless Women and Children: Opportunities for Training," Jefferson Journal of Psychiatry. Vol. 8 : Iss. 2 , Article 9.

DOI: https://doi.org/10.29046/JJP.008.2.006

Available at: https://jdc.jefferson.edu/jeffjpsychiatry/vol8/iss2/9

This Article is brought to you for free and open access by the Jefferson Digital Commons. The Jefferson Digital Commons is a service of Thomas Jefferson University's Center for Teaching and Learning (CTL). The Commons is a showcase for Jefferson books and journals, peer-reviewed scholarly publications, unique historical collections from the University archives, and teaching tools. The Jefferson Digital Commons allows researchers and interested readers anywhere in the world to learn about and keep up to date with Jefferson scholarship. This article has been accepted for inclusion in Jefferson Journal of Psychiatry by an authorized administrator of the Jefferson Digital Commons. For more information, please contact: JeffersonDigitalCommons@jefferson.edu. 


\title{
Working With Homeless Women and Children: Opportunities for Training ${ }^{1,2}$
}

\author{
Lance D. Clawson, M.D. \\ Ronald J. Koshes, M.D.
}

\begin{abstract}
The diversity of the homeless population allows for unique training opportunities in psychiatry, especially for child and adolescent psychiatry fellows. The prevalence of psychopathology both existing in and as a result of displacement and disenfranchisement requires a specialized knowledge of this population and provides an extraordinary education in community outreach, emergency psychiatry and social service delivery systems. The authors review their experience of working with homeless women and children in the community. Possibilities for more comprehensive training and research are also presented.
\end{abstract}

\section{INTRODUCTION}

Not all homeless individuals are mentally ill. In fact, the majority do not suffer from mental illness. It is estimated that between $30-40 \%$ in any given city or shelter suffer from a major mental disorder. Additionally, as many as $60 \%$ of homeless individuals can be diagnosed with substance abuse or dependence $(1,2,3)$. The added impairment by alcohol and drugs threatens the ability of an individual to extricate him or herself from homelessness. When homeless children and families are considered alone (mostly single parent families), the degree of mental illness and substance abuse and dependence reaches nearly $30 \%$ (4), and it is expected that this figure will rise as the problem of addictive drugs in urban settings continues to grow.

Taken separately, the problems of homeless women become of immediate concern. In a one year period in Massachusetts, 1,407 women and 1,942 of their children were sheltered in battered women's programs. An additional 3,087 were turned away because of lack of space (5). Unfortunately, only about half of

\footnotetext{
${ }^{1}$ Presented 16 February, 1989 at the Annual Meeting of the Association of Military Child Psychiatrists, Reno, Nevade.

${ }^{2}$ NOTICE: The views of the authors do not purport to reflect the position of the Department of the Army or the Department of Defense. (para 4-3, AR 360-5)

Address correspondence to Dr. Koshes, Uniformed Services University of Health Sciences, F. Edward Hebert School of Medicine, Fort Lee, VA 23801
} 
the surveyed shelters responded, leaving complete data unobtainable. Considering the age differences of homeless women, those with children are more likely to have substance abuse problems, while those who are older may suffer more from chronic psychotic illnesses (6). Additionally, the stress encountered when families are displaced and sometimes fragmented parallels the incidence of psychopathology seen in disaster victims. Often the ability to plan and react is inhibited and dysfunctional behavior occurs even in the absence of preexisting psychopathology (7).

In all, the problems of homeless children and families represent potentially the most serious problem facing the community mental health system today. This presents a challenge for community planners as well as mental health professionals. Recent attention has been given to the need for a new curriculum in community psychiatry. Both Mosher and Burti (8) in their new textbook of community psychiatry and Goldman and Morrissey (9) describing the "new cycle" of mental health reform, advocate an on-site approach to the delivery of mental health services. It appears that wider attention is now being given in the training of residents to this effective system of service delivery as evidenced by the development of curricula and training programs in psychiatry which focus on the particular needs of chronic mentally ill individuals in the community $(10,11)$. The following account offers a perspective on training opportunities for the child and adolescent psychiatry fellow using an "on-site" approach to psychiatric service delivery.

\section{BEGINNING WORK WITH THE HOMELESS}

In early 1987, the Washington Psychiatric Society announced the formation of the Committee for the Homeless. A request for interested psychiatrists in the community to volunteer in order to serve this population was presented to the membership by the new Committee Chairman. Even though only one person responded, he was a faculty member of one of the local medical schools with direct contact to psychiatric residents.

With a group of two forming the committee, the manpower issue was of principle concern. The faculty member was able to interest the authors in providing services to the mentally ill homeless and shortly afterwards it became clear that this experience provided an opportunity for other residents to learn both community and emergency psychiatry in an underserved and exciting setting. Various residency programs were visited and residents were recruited to work in the shelters. The response initially was slow as programs struggled to accommodate extra training time into busy residents' schedules as well as address issues of service needs at their own medical centers, as well as malpractice coverage. Mostly, program directors were concerned that the experience was not unique and would offer residents little more than a change of setting in the delivery of services.

For us, the emergency training at Walter Reed Army Medical Center clearly 
did not provide experience with unmedicated, acutely psychotic individuals off the street who were impaired in multiple biopsychosocial spheres. This was quite unusual given that the mission of the military psychiatrist is to prepare for the possibility of providing services to acutely mentally ill individuals in times of personnel shortage and adverse working conditions. Several military psychiatrists have discussed the need for trainees to develop skills in crisis management in the community and the ability to provide triage and referral. They advocate a community-based mental health network which seeks to rapidly integrate afflicted individuals into the mainstream of the fighting force $(12,13)$.

It is with little effort that the work of these authors can be applied to the current homeless situation involving mentally ill individuals. For instance, the notion of proximity, immediacy, and expectancy (P.I.E.) practiced in military psychiatry (14) has been noted elsewhere in working with the chronic mentally ill homeless in similar terms $(15,16)$. It therefore became expedient to work closely in the development of this training program not only for the important social value of the work, but for the training provided in what may be seen as disaster management in the community.

What has grown out of our initial efforts with the support of the Washington Psychiatric Society and the Washington, D.C. psychiatry residency programs is a formal elective experience for psychiatric residents. A curriculum outlining the objectives and behavioral expectations of the experience has been developed and serves as a reference as well as an orienting device for working with the homeless. Fourteen psychiatry residents have provided ongoing services at six of the city's homeless shelters ranging from urgent psychiatric evaluations, staff consultations, substance abuse and dependence referrals and both individual and group psychotherapy.

When one of us (Clawson) was accepted into the Child and Adolescent Psychiatry Fellowship at Walter Reed Army Medical Center, the possibilities for continued participation in this elective was threatened due to time constraints and lack of available supervision. Fortunately, the time was available and the service delivery needs abundant at a local women's shelter, which is described below.

\section{THE WOMEN'S SHELTER}

Her Space is contained within a large brownstone in a lower income section of Washington, D.C. The program has, after a period of restructuring and much needed psychiatric consultation, evolved from a strictly "shelter" oriented facility to one which attempts to provide psychosocial rehabilitation as well. The program is broken up into a 30 day shelter program which assesses and provides for the needs of 3-4 homeless and/or battered women and their children, and a longer stay independent living phase. This second phase is an additional 2 to 5 months of housing in group apartments which are available to 10 families who are able to integrate into this model of rehabilitation. Although Her Space 
began as a shelter for battered women and their families, it has evolved over the past several years into what one might consider a shelter for homeless mothers and their families, given, as we will later show, the distinction between battered women without a place to go and homeless women is becoming progressively blurred. The emphasis on family violence is still ever present.

Each family has a case worker, who does basic social work tasks in getting social security benefits, obtaining Medicare and Welfare, enrolling the children in school, helping to liaison with the school and other outside agencies concerned with the well being of the children, and getting the mothers and their children to their much needed medical, legal, and work-related appointments. The case worker and an assigned "Life Coach" also serve as personal counselors to each family, attempting to provide much needed social support and positive modeling to these isolated families, and monitoring the families' general and individual well-being. The initial 30 day program also provides some daycare and special activities for the children and mothers. Now integral to the program is a group therapy experience lead by a volunteer psychiatrist for the mothers to address their individual issues twice weekly.

One of us (Clawson) has been working weekly at the shelter, principally where the families live. Not only are psychiatric services made available on-site, but the overall commitment to delivering the services in an on-going fashion is, we feel, an essential aspect of engaging these individuals in useful and therapeutic work. The attempts at secondary prevention have taken the form of initiating the collection of a thorough demographic and psychosocial data base on each mother and child, the assessment through consultation to the case managers on each case, and direct contact with the mothers and their children to determine the presence of psychiatric disorders which require prompt referral and treatment.

In the area of primary prevention a number of interventions have been attempted. In the initial 30 day segment, the idea of an environment which facilitates a supportive atmosphere, and one which expects a certain level of personal responsibility from each of the mothers and children is created. This is accomplished through consultation to the program coordinator and counselors on issues of individual and group psychopathology, staff boundaries and their need for staying in role as counselors and case workers (to prevent too much projective identification and splitting), program rules and limits and how they are followed, availability of staff to the inhabitants for counselling, amount which is done for the mothers versus what they are expected to do, and issues around contingencies for desired and undesired behavior.

Additionally, each child under the age of 12 is on a star chart to reinforce certain target behaviors. Adolescents are placed on contingency contracts if certain behaviors are problematic. Workers intend to create a milieu where all involved support each other to make adaptive changes in their lives. This is 
accomplished by using the concepts of empathy, personal responsibility, and consideration of the entire family in decision making.

A latency age group is held which focuses on expression of appropriate feelings, family concerns, sharing and mutual support through play and talking activities. A similar group is lead for the adolescents (11 to 15), where past trauma, drug abuse, current concerns and developmental issues such as personal identity, individuation and separation from the family are addressed through art, therapeutic games, diaries and talking activities.

Finally, an ongoing parenting group explores issues such as child discipline, creating positive versus solely negative interactions with their children, improving family unity, and addressing violence towards their children, as well as specific problem-solving around specific mother-child or sibling conflicts. Additionally, the groups aid in the diagnosis and disposition of the individual shelter members.

\section{RESEARCH DATA}

Clearly research with the homeless and homeless mentally ill is an area of concern. Previous research efforts have centered on the demography of this population, while now effective treatment configurations are needed and being studies in most of the subgroups of homeless individuals $(17,18)$.

The literature on homeless families is, however, quite sparse. Of 80 sheltered families studied in Massachusetts, the following characteristics were present:

\begin{tabular}{|c|c|}
\hline Median Age & 27 \\
\hline Minority Race & $52 \%$ \\
\hline High School Education & $37 \%$ \\
\hline Unmarried & $45 \%$ \\
\hline Contact with Mental Health Services & $24 \%$ \\
\hline Personality Disorders & $71 \%$ \\
\hline Major Psychiatric Disorders & $27 \%^{3}$ \\
\hline
\end{tabular}

In evaluating the 151 children, 81 of whom were under five years old, the Denver Developmental Screening Test revealed an incidence of $47 \%$ of children with developmental lags; over $15 \%$ had four or more lags. Language acquisition delays and personal and social growth were retarded in about a third of the same. If the same data collection were applied to children over five years old, a similar prevalence of developmental and social abnormalities was seen (4). In an analysis of homeless mothers as compared to mothers who were housed, a serious deficiency in available personal and social supports was noted. Fully two-thirds of the homeless mothers had previously resided in shelters or welfare

\footnotetext{
${ }^{3} 10 \%$ major affective disorders, $9 \%$ substance abuse (probably underreported), $5 \%$ with mental retardation, and $3 \%$ with schizophrenia.
} 
hotels, whereas very few housed mothers had this experience. This would seem to indicate that a learned behavior or perhaps negatively reinforced role was being generated (19).

\section{CHARACTERISTICS OF THE STUDY SHELTER}

There were fourteen families which entered the Her Space program over a six month period. Nearly all shelter residents have been black, the mothers ranging in age from 19 to 39 , the mean age being about 25 years. All families are from the greater Washington, D.C. metropolitan area, although about one third did not originate there. Of the families that originated in the Washington, D.C. area, none were on good terms with their extended families and could not rely on them for support. Over $80 \%$ of the mothers had a high school diploma or General Education Degree, and $14 \%$ had a few years of college or technical schooling. Approximately $70 \%$ of the mothers give a history of physical and/or sexual abuse as a child, and $90 \%$ give a history of physical abuse as an adult, although not necessarily in the recent past prior to entering the shelter. The history of abuse is confounded by the fact that abuse is a relative criteria for gaining admission to the program, and therefore fabrication does occur. Approximately $40 \%$ of the families had not been in a stable residence prior to coming to the shelter, about $50 \%$ have resided in other forms of shelter housing in the past several years.

The children ranged in age from 18 months to 15 years. The average age was 5.8 years. Of the 25 children, 15 were girls, 10 were boys. With close observation, all children related fears and concerns as to injury or loss of their mothers, or injury to themselves. All of the children presented as very needy and attention hungry. Four of the boys were experiencing age-inappropriate enuresis after entering the shelter, while none of the girls were. Two boys and two girls were experiencing new onset nightmares while in the shelter. One 3 year old boy was highly suspicious for the presence of pervasive developmental disorder, but testing was incomplete. Two girls and 3 boys qualified for separation anxiety disorder. One nine-year-old boy with enuresis and nightmares also was experiencing exaggerated fears of intruders, and compulsively checked windows and doors whenever he detected noises in the environment. One sixyear-old boy qualified for the diagnosis of attention deficit disorder of the hyperactive type. The three oldest girls had been sexually abused prior to entering the shelter, and about $40 \%$ of the children had been physically abused, boys and girls about equally.

What does not stand out in the description of the families, but seems clear from our experience in the shelter was that there were two subpopulations of the mothers. About $20 \%$ fit the traditional picture of the battered woman's shelter resident. They were older, had previous stable work and residence histories, and had finally left their husbands due to many years of physical abuse. Because of factors such as no family in the area and being out of the work force for a 
number of years, they turned to the shelter for assistance. The other $80 \%$ seemed to fit closely the description previously described by Bassuk et al (4). What is clear then is the emergence of relatively adaptive individuals, who for either economic reasons, or personal safety have been displaced. The goal of placement of psychiatric support at the shelters would appear to be a prevention of acute homelessness from progressing towards chronic homelessness. Reintegrating these individuals back into the community was indeed the goal of the various programs at Her Space and a specific aim of the psychiatric consultation. Rigorous treatment research on the effectiveness of these interventions has not been attempted as of yet. The following clinical vignettes of mothers' and childrens' successful community reintegration provide models for effective psychiatric interventions.

\section{SELECTED CLINICAL VIGNETTES}

Janet fits the more typical model of the homeless single mother. She is a 34year-old black female with a high school diploma, who came to the shelter after her boyfriend raped her oldest daughter (age 13). Janet and her two daughters had been living with him for several months. The biologic father's location are unknown, having deserted the family about five years ago. Since then, the family has been wandering from boyfriend to boyfriend and through several shelters and friend's homes. Sasha (age 9), the youngest daughter has leukemia in remission, and has been treated locally at a university medical center. Sasha is very needy and disruptive. She becomes very agitated and tearful, striking out physically, whenever her mother leaves the shelter for work or errands. Julie (age 13), is doing well in school and was beginning to express her fears of men and traumatic experiences while living in the shelter. Janet has occasional employment, and has difficulty keeping jobs and residences due to her explosive nature, often making violent threats towards others. She abuses crack and marijuana. She was asked to leave Her Space after a number of warnings when she threatened one of the staff with a knife. The family moved to a temporary apartment in Janet's father's building, which was difficult for Janet because both her father and uncle had both sexually abused her there as a child.

Susan is a 33-year-old black female originally from New Orleans who was married for 16 years to a government worker. He often became drunk and struck Susan. She finally left with 3 of her 4 children when he threatened her with a knife. Her oldest daughter (age 15), soon joined the family at the shelter after her father began physically abusing her. Susan felt she could not return to New Orleans to live with her mother due to poor prospects for employment there. Susan was a very passive individual, but with encouragement was able to get public assistance and housing, day care for her 18-month-old daughter while she is at work, and a psychiatric evaluation for her son who has enuresis, nightmares, and phobic/compulsive symptoms. Susan and her children moved 
to an apartment with public assistance after $3 \frac{1}{1} 2$ months at Her Space, and worked as an aid at a local nursing home.

\section{CONCLUSIONS}

Working with homeless children, adolescents and families can broaden the psychiatric trainee's perspective on community interventions with underserved individuals. The unique features of this population include the multiple biopsychosocial impairments of individuals and families, as well as the diagnostic challenges in child and adolescent psychiatry which they present to the trainee. The ability to make assessments and deliver services as close to the sector of need as possible, enables the trainee to experience first-hand the principles of disaster management, as well as to focus on primary and secondary prevention in the community.

\section{REFERENCES}

1. Gelberg L, Linn LS, Leake BD: "Mental health, alcohol and drug use, and criminal history among homeless adults;” American Journal Psychiatry 145:191-196, 1988

2. Herman $\mathrm{H}$, et al: "Prevalence of severe mental disorders in disaffiliated and homeless people in inner Melbourne;” American Journal of Psychiatry 146(9):1179-1184, 1989

3. Susser E, Struening E, Conover S: "Psychiatric problems in homeless men;” Archives of General Psychiatry 46:845-850, 1989

4. Bassuk EL, Rubin L, Lauriat AS: "Characteristics of sheltered homeless families;" American Journal of Public Health 76(9):1097-1101, 1986

5. Ryback RR, Bassuk EL: "Homeless battered women and their shelter network;" New Directions For Mental Health Services 30:55-61, 1986

6. Bachrach LL, Nadelson CC: "Chronically mentally ill women: an overview of service delivery issues;” in Treating Chronically Mentally Ill Women. Washington, D.C.: American Psychiatric Press, Inc., pp. 3-17, 1988

7. Caplan G: population-oriented psychiatry. New York: Human Sciences Press, Inc., pp. 38-40, 1989

8. Mosher LR, Burti L: Community mental health: principles and practice. New York: WW Norton \& Company, pp. 91-108, 1989

9. Goldman $\mathrm{HH}$, Morrissey JP: “The alchemy of mental health policy: homelessness and the fourth cycle of reform;" The American Journal of Public Health 75:727731,1985

10. Falukner LR, et al: "A basic residency curriculum concerning the chronically mentally ill;" American Journal of Psychiatry 146(10):1323-1328, 1989

11. Koshes RJ, Clawson LD, Voell JW: "A residency elective in care of the homeless mentally ill;" Hospital and Community Psychiatry 40(10):1 104, 1989

12. Bushard B: "The U.S. army's mental hygiene consultation service;" symposium on Preventive and Social Psychiatry. Washington, D.C.: Walter Reed Army Medical Center, and the National; Research Council 15-17 April, pp. 431-43, 1957

13. Hausman W, Rioch D: "Military psychiatry: a prototype of social and preventive psychiatry in the United States;” Archives of General Psychiatry 16:727-739, 1967 
14. Artiss KL: “Human behavior under stress;" Military Medicine October: 1011-1015, 1963

15. Levine IS, Lezak AD, Goldman HH: "Developing community support systems for the homeless who are seriously mentally ill;" New Directions for Mental Health Services 30:1986

16. Adler DA, Levinson DJ, Astrachan BM: "The concept of prevention in psychiatry;" Archives of General Psychiatry 35:786-789, 1978

17. Tessler RC, Dennis DL: A synthesis of NIMH-funded research concerning persons who are homeless and mentally ill. Rockville, Maryland: National Institute of Mental Health, 1989

18. Sargent M: Update on programs for the homeless mentally ill; Hospital and Community Psychiatry 40(10):1015-1016, 1989

19. Bassuk EL, Rosenberg L: "Why does homelessness occur? A case-control study;" American Journal of Public Health 78(7):783-788, 1988 